\title{
Adsorption of chlorendic acid onto hydrophilic fumed titanium dioxide (P25)
}

\author{
Ndokiari Boisa
}

Dept. of Chemistry, Faculty of Science, Rivers State University of Science and Technology, P.M.B. 5080, Port Harcourt, Nigeria

\section{Email address:}

talk2boisa@yahoo.com

\section{To cite this article:}

Ndokiari Boisa. Adsorption of Chlorendic Acid onto Hydrophilic Fumed Titanium Dioxide (P25). American Journal of Environmental Protection. Vol. 2, No. 6, 2013, pp. 183-187. doi: 10.11648/j.ajep.20130206.20

\begin{abstract}
The adsorption behavior of chlorendic acid (1, 4, 5, 6, 7, 7-hexachlorobicyclo-(2, 2, 1) -hept-5-ene-2, 3dicarboxylic acid) onto hydrophilic fumed $\mathrm{TiO}_{2}(\mathrm{P}-25$, Degussa) in aqueous suspension was investigated. Results indicate that chlorendic acid adsorbed strongly in short times (2-5 mins) onto $\mathrm{TiO}_{2}$. Adsorption data is consistent with LangmuirHinshelwood isotherm model for monolayer adsorption and the shape of the isotherm indicates second order behavior. Calculated adsorption constant $\mathrm{K}$, and maximum adsorbable quantity at $20^{\circ} \mathrm{C}$ were obtained as $(0.12 \pm 0.03) 1 / \mathrm{mg}$ and $(4.4$ $\pm 0.2) \mathrm{mg} / \mathrm{g} \mathrm{TiO}$ respectively. Adsorption of chlorendic acid in water onto $\mathrm{TiO}_{2}$ is exothermic.
\end{abstract}

Keywords: Adsorption, Reactive Flame Retardant, Titanium Dioxide

\section{Introduction}

Chlorendic acid $\left(\mathrm{C}_{9} \mathrm{H}_{4} \mathrm{Cl}_{6} \mathrm{O}_{4}\right)$ (CAS No. 115-28-6) (Figure 1) is used as a chemical intermediate in the manufacture of polyester resins, polyurethane foams, wool fabric alkyd resin paints, oligoesters, piping and engineering plastics, and its incorporation is aimed at imparting flame resistance to products [1]. Currently it is used in the synthesis of functional metal organic frameworks (MOFs) [2]. Chlorendic acid is also used as an extreme pressure lubricant [1]. The hexachloronorborene structure within chlorendic acid renders it inert to chemical degradation [3], and attempted thermal degradation studies have also not been very efficient [e.g. 4]. Human population may be exposed to chlorendic via dermal contact and inhalation routes [1]. Due to its several industrial applications chlorendic acid is released as industrial waste [3]. When it enters the environment through wastewater, it is expected to favor aqueous compartment because of its solubility in water. A concentration of $450 \mathrm{mg} / \mathrm{L}$ has been observed for chlorendic acid in one landfill leachate [5].

In the last half century, numerous advancements have been made to combat increasing pollution discharged into water bodies and physical processes like adsorption, polymer sorption and certain membrane processes are currently been investigated as methods of removing organics from water. In recent years there has been great interest in the use of advanced oxidative processes (AOPs) for the destructive removal of hazardous and refractive organic compounds [6]. Heterogeneous catalysis by semiconductors (e.g. $\mathrm{TiO}_{2}$ ) is emerging AOPs. Titanium dioxide undergoes photo-excitation in the presence of UVvisible radiation $(<400 \mathrm{~nm})$ and this special characteristic has made it one of the semiconductors of interest in the subject area of organic pollutants removal [7-8]. Pioneering application of titanium dioxide for environmental cleaning was by Bard in 1979 [9].

Fujishma et al [10], Hoffman et al [11] and Vijaikumar et al [12] have at different times reported the advantages of using titanium dioxide photocatalyst for environmental clean-up. A classical heterogeneous catalysis process can be separated into five steps [13]: transfer of the reactants in the fluid phase to the surface, adsorption of at least one of the reactants, reactions by the adsorbed reactants, desorption of the product(s) and removal of the products from the interface region.

The relevance of adsorption step to understanding solid catalysts aided degradation of known organic contaminants in water cannot be over-emphasized. Consequently several studies have been conducted to investigate the adsorption behavior of priority organic chemicals on $\mathrm{TiO}_{2}$ surfaces in aqueous systems (e.g. 6, 14 - 15). The rate of adsorption $\mathrm{R}_{\mathrm{a}}$ is [17]:

$$
\mathrm{R}_{\mathrm{a}}=\mathrm{K}_{\mathrm{a}}[\mathrm{A}](1-\theta)
$$


Where $\mathrm{K}_{\mathrm{a}}$ is a rate constant relating to the adsorption process

The rate of desorption $R_{d}$ is proportional to the number of molecules attached to the surface, which implies proportionality to the fraction of surface covered.

$$
\mathrm{R}_{\mathrm{d}}=\mathrm{K}_{\mathrm{d}} \theta
$$

When rate of adsorption and desorption are equal

$$
\mathrm{K}_{\mathrm{a}}[\mathrm{A}](1-\theta)=\mathrm{K}_{\mathrm{d}} \theta
$$

or

$$
\theta /(1-\theta)=\left(\mathrm{K}_{\mathrm{a}} / \mathrm{K}_{\mathrm{d}}\right)[\mathrm{A}]_{\mathrm{e}}
$$

the ratio $\left(\mathrm{K}_{\mathrm{a}} / \mathrm{K}_{\mathrm{d}}\right)$ is an equilibrium constant, $[\mathrm{A}]_{\mathrm{e}}$ is equilibrium concentration and replaced with $\mathrm{K}$ :

$$
\theta /(1-\theta)=\mathrm{K}[\mathrm{A}]_{\mathrm{e}}
$$

or

$$
\theta=\mathrm{K}_{\mathrm{a}}[\mathrm{A}] /\left(1+\mathrm{K}[\mathrm{A}]_{\mathrm{e}}\right)
$$

For any system obeying the Langmuir-Hinshelwood model, a plot of $\theta$ (fraction of surface covered) against [A] is expected to yields an isotherm. However, due to surface imperfections certain adsorbents exhibit unexpected adsorption behavior [17]. Consequently there is need to investigate the adsorption of water pollutants with known human and ecological health implication onto emerging photocatalysts like $\mathrm{TiO}_{2}$. Adsorption data for a specific water pollutant can facilitate the design of efficient remediation protocols. The aim of this work was to understand and describe the adsorption of structurally bulky diacids onto $\mathrm{TiO}_{2}$ (P-25 degussa) using chlorendic acid since the adsorption properties of this class of diacids onto $\mathrm{TiO}_{2}$ have been investigated.

\section{Materials and Method}

Hydrophilic fumed titanium dioxide (P25) (98\% purity) was purchased from BDH Merck limited Pole Dorset, United Kingdom and used without further purification. The reactive flame retardant, chlorendic acid $(1,4,5,6,7,7$ hexacloro-5-norborene-2,3-dicarboxylic acid) (99\% purity) was purchased from Sigma-Aldrich Logistik GmbH, Germany, and used as received.

\subsection{Adsorption}

To investigate the influence of temperature an aqueous suspension of chlorendic acid, $600 \mathrm{mgL}^{-1}(20 \mathrm{~mL})$ and $\mathrm{TiO}_{2}$ $(0.1 \mathrm{~g})$ was prepared in $100 \mathrm{~mL}$ Pyrex beaker and left in a thermostatic bath in the dark for one hour to permit the adsorption/desorption equilibrium to be reached at different temperatures $\left(22,30,35\right.$ and $\left.40{ }^{\circ} \mathrm{C}\right)$. After equilibration 3 $\mathrm{ml}$ of each suspension was siphoned off with pipette, centrifuged (Centaur MSE centrifuge instrument) for 15 mins at 2700 RPM. Small portions of the resulting supernatant were siphoned with a syringe and filtered through Whatman syringe filter (Whatman filter paper pore size: $0.2 \mu \mathrm{m}$ ) to remove $\mathrm{TiO}_{2}$ particle still suspended in the supernatant. The resulting clear liquids were analyzed with high performance liquid chromatography-diode array detector (HPLC-Dad) equipment at a selected wavelength to obtain the equilibrium concentration of chlorendic acid. The amount chlorendic acid adsorbed per gram of $\mathrm{TiO}_{2}$ and the maximum amount of the acid adsorbed were determined according to the derived Langmuir equation after linearization (equation 6).

Other adsorption studies were conducted at $20 \pm 2{ }^{\circ} \mathrm{C}$. Stirred aqueous suspensions $(20 \mathrm{~mL})$ of chlorendic acid (200, 300, 400 and $500 \mathrm{mgL}^{-1}$ concentrations) and $\mathrm{TiO}_{2}$ $(0.1 \mathrm{~g})$ in $100 \mathrm{~mL}$ Pyrex beakers were left for specific times $(10,20,30,40,50$ and $60 \mathrm{~min})$ in dark. After the equilibration $3 \mathrm{~mL}$ of each suspension was siphoned, centrifuged and filtered as in the first adsorption study to obtained clear supernatants for further analysis

\subsection{Analytical Measurements}

The UV-visible absorption spectrum of $100 \mathrm{mgL}^{-1}$ chlorendic acid was recorded using Evolution 300 (Thermo Electron Corporation) spectrophotometer. The UV-visible spectrophotometer was set at; scan interval: 190-300nm, spectral bandwidth: $1.5 \mathrm{~nm}$, integration time: $1.0 \mathrm{sec}$, path length: $1 \mathrm{~cm}$, cell type: quartz and lamp: xenon. Chlorendic acid concentrations were monitored by high performance liquid chromatography-diode array detector (HPLC-Dad) using a Varian 9050 HPLC system interfaced with a Jasco PU-980 pump and a SP 4270 integrator. A good quantification was achieved using reverse-phase column [ODS 2 spherisorb C18, $5 \mu \mathrm{m}(150 \times 4.6) \mathrm{mm}$ ] and the detector with a wavelength at $221 \mathrm{~nm}$. The mobile phase was composed of the following: $60 \%$ acetonitrile, $40 \%$ water with $\mathrm{pH}$ adjusted using $0.05 \%$ acetic acid, and at a flow rate of $1 \mathrm{ml} \mathrm{min}^{-1}$. For quality control nine calibration solutions of concentrations ranging from 10 to $500 \mathrm{mg} / \mathrm{L}$ were prepared from $1000 \mathrm{mg} / \mathrm{L}$ stock solution. The solutions were analysed with HPLC instrument for the generation of a calibration plot (Figure 2).

\section{Results and Discussion}

\subsection{Adsorption}

Results of adsorption experiments of chlorendic acid on $\mathrm{TiO}_{2}$ are shown in Figure 3. The isotherm (Figure 3) was obtained by plotting the amount of chlorendic acid adsorbed versus solute concentration in the equilibrium solution. The shape of the isotherm indicates L (Langmuir) 2-type behavior according to Giles, Smith and Huitson classification of adsorption isotherms for solutes in dilute solution [19]. According to their classification the adsorption of chlorendic acid on $\mathrm{TiO}_{2}$ proceeds until a monolayer is established, without the formation of further layers. The pattern of the isotherm (Figure 3) is indicative 
of high attraction between chlorendic acid molecules and the sorbent surface. $\mathrm{TiO}_{2}(\mathrm{P}-25)$ effectively removes chlorendic acid at low initial concentrations; however, at higher concentrations the isotherm reaches a maximum capacity as highlighted by the plateau. The L2-type isotherms are usually associated with the adsorption of ionic chemicals in water (e.g. metal cations, phenols, reactive dyes) [20-25]. The linear graph (Figure 4) with correlation coefficient of 0.9998 obtained for the adsorption chlorendic acid onto $\mathrm{TiO}_{2}$ indicates that the data obtained fits the Langmuir-Hinshelwood adsorption model well.

The slope corresponds to the inverse of maximum adsorbable quantity of the acid, and the intercept is equivalent to the inverse of the product of the equilibrium constant for adsorption and the maximum quantity of chlorendic acid adsorbed by $\mathrm{TiO}_{2}$.

The maximum adsorbable amount of chlorendic acid onto $\mathrm{TiO}_{2}$ at $20{ }^{\circ} \mathrm{C}$ is $4.34 \pm 0.2 \mathrm{mg} / \mathrm{g} \mathrm{TiO}_{2}\left(1.1 \times 10^{-5} \mathrm{~mol}\right.$ chlorendic acid/g $\mathrm{TiO}_{2}$ ). The adsorption maximum value obtained for chlorendic acid from this work is significantly below the range $6.2-7.3 \times 10-5 \mathrm{~mol} / \mathrm{g} \mathrm{TiO}_{2}$ (Table 1) obtained for smaller diacids by Robert et al [26]. The lower adsorption maximum value obtained for chlorendic acid onto $\mathrm{TiO}_{2}$ in this study compared to oxalic acid, malonic acid, succinic acid and methylsuccinic acid molecules is not unexpected because Wong et al [27] have previously observed that smaller organic molecules have superior adsorption capacities. Their superior adsorption capacities are due to the fact that the smaller molecular size organic acids are able to penetrate deeper into the pore structure of the adsorbent particles [27].

\subsection{Adsorption Equilibration}

Figure 5 shows that the adsorption of chlorendic acid onto $\mathrm{TiO}_{2}$ was achieved very fast $(<5$ mins) between 200 $500 \mathrm{mgL}^{-1}$ concentration range. The observed spontaneous adsorption of chlorendic acid onto $\mathrm{TiO}_{2}$ in this study is consisted with the short times previously recorded for diacids by Robert et al [26]. Based on diffuse reflectance FTIR data it has been suggested that adsorption of chlorendic acid-like molecules onto $\mathrm{TiO}_{2}$ proceeds very fast via titanium carboxylate formation [26].

\subsection{Influence of Temperature on Adsorption}

Figure 6 shows preliminary results of chlorendic acid adsorption onto $\mathrm{TiO}_{2}$ surface as a function of temperature. At the natural $\mathrm{pH}$ of the suspension, removal of chlorendic acid from aqueous solutions decreased with increase in temperature up to $40{ }^{\circ} \mathrm{C}$. The drop in adsorption with increasing temperature is not unexpected since heat is typically evolved after bond formation between solute and adsorbent [28]. The reduction in the adsorption capacity of $\mathrm{TiO}_{2}$ with increasing temperature (between $20-40{ }^{\circ} \mathrm{C}$ ) is consistent with that of perlite (a glassy volcanic rock material) [29]. However some examples have been reported where adsorbed organic molecules increase with temperature [e.g. 21]. The spontaneous removal of chlorendic acid from water by $\mathrm{TiO}_{2}$ and the exothermic nature of the adsorption process indicate that alluvial contamination of the flame retardant could be remediated using $\mathrm{TiO}_{2}$.

\section{Conclusion}

Adsorption behavior of chlorendic acid on $\mathrm{TiO} 2$ (Degussa, P-25) has been investigated. Specific conclusions established from the study are:

1. The results indicate that chlorendic acid adsorbs spontaneously onto $\mathrm{TiO}_{2}$ in the dark (equilibrium was attained in less than 5 mins).

2. Adsorption data obtained from this work fitted the Langmuir-hinshelwood isotherm model for monolayer adsorption well.

3. Adsorption constant and maximum adsorbable quantity obtained for chlorendic acid at $20{ }^{\circ} \mathrm{C}$ were $(0.12 \pm 0.03) \mathrm{l} / \mathrm{mg}$ and $(4.4 \pm 0.2) \mathrm{mg} / \mathrm{g} \mathrm{TiO}_{2}$

4. Temperature increase from $22-40{ }^{\circ} \mathrm{C}$ reduces adsorption of chlorendic acid onto $\mathrm{TiO}_{2}(\mathrm{P}-25)$.

5. Since chlorendic acid remains a raw material for the production of several polymeric items, more studies investigating its clean-up from contaminated water bodies should be conducted.

\section{Acknowledgements}

The author would like to acknowledge the Government of Rivers State, Nigeria for the sponsorship of the corresponding author during his period of study at the Northumbria University, UK.

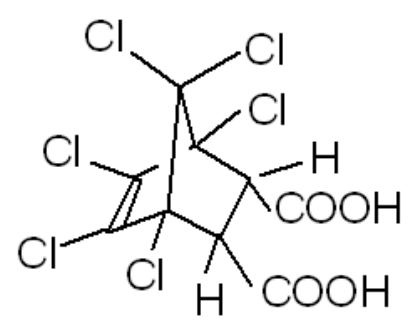

Figure 1. Molecular structures of chlorendic acid

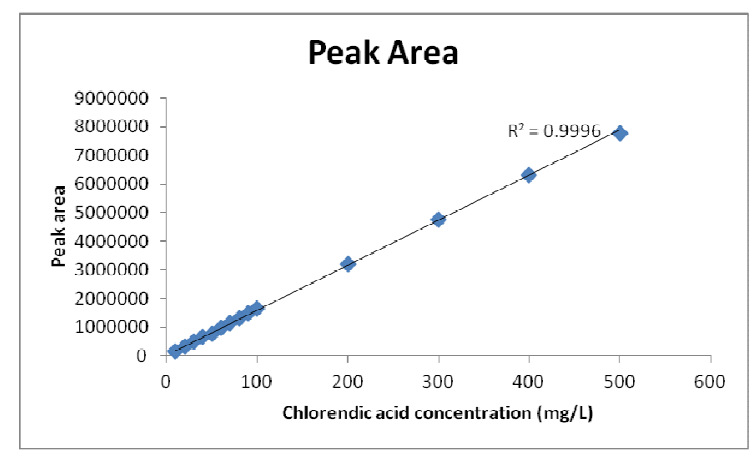

Figure 2. HPLC calibration plot obtained for chlorendic acid 


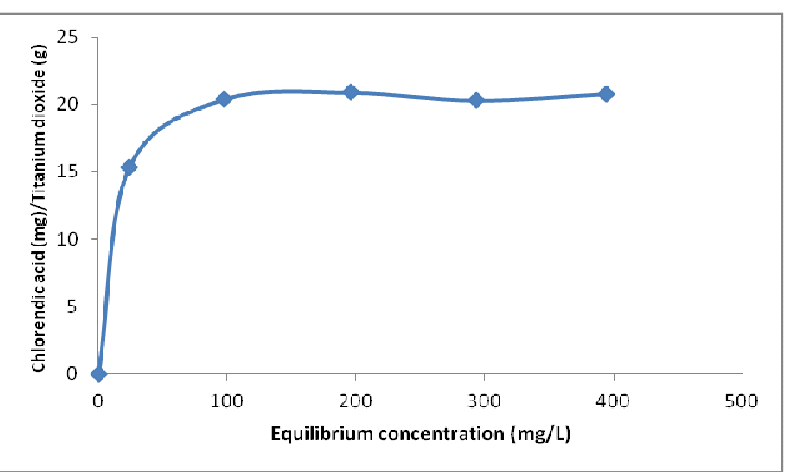

Figure 3. Adsorption isotherm of chlorendic acid. Concentration range: $100-500 \mathrm{mgL}^{-1}$. Temperature: $20^{\circ} \mathrm{C}$. Line: Langmuir model

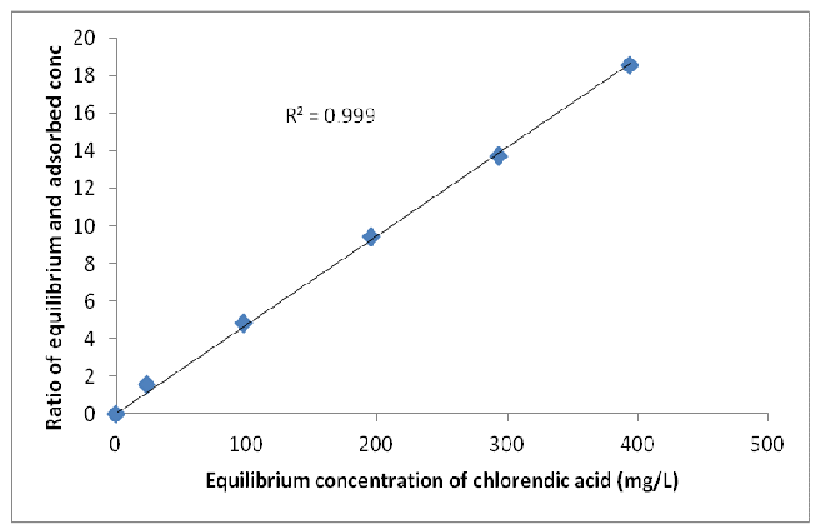

Figure 4. Linear transform of the Langmuir isotherm

Table 1. Comparison of adsorption characteristic for some diacids and chlorendic acid

\begin{tabular}{lll}
\hline Name of compound & $\begin{array}{l}\mathbf{W}_{\max }\left(\mathbf{x ~ 1 0} \mathbf{~}^{-5} \mathbf{~ m o l} / \mathbf{g}\right. \\
\left.\mathbf{T i O}_{2}\right)\end{array}$ & Authors \\
\hline Oxalic acid & 7.3 & Robert et al [26] \\
Malonic acid & 7.2 & Robert et al [26] \\
Succinic acid & 6.7 & Robert et al [26] \\
Methylsuccinic acid & 6.2 & Robert et al [26] \\
Chlorendic acid $\left(20^{\circ} \mathrm{C}\right)$ & 1.1 & This work \\
\hline
\end{tabular}

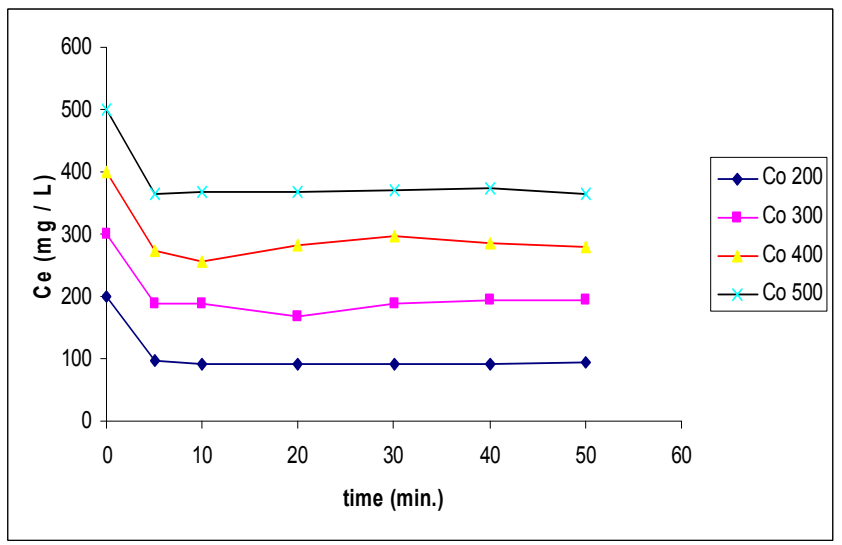

Figure 5. Plot of equilibrium concentrations (Ce) vs adsorption times for initial concentrations (Co) 200-500 $\mathrm{mg} / \mathrm{L}$

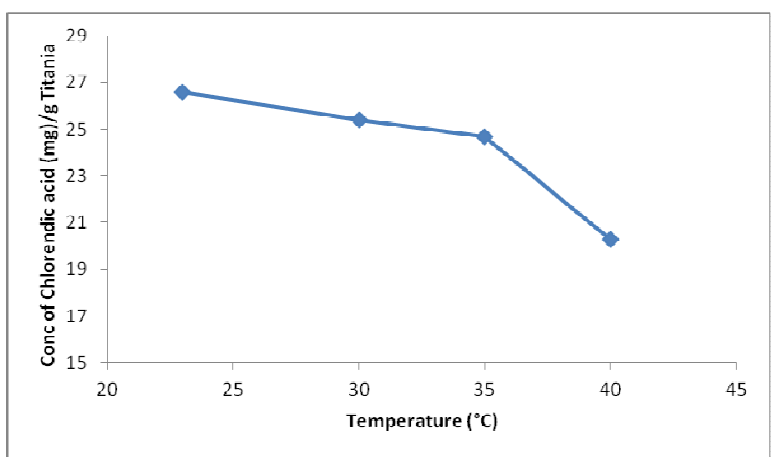

Figure 6. Chlorendic acid adsorbed on $\mathrm{TiO}_{2}$ as a function of temperature

\section{References}

[1] HSDB. 2013. Hazardous Substances Data Bank. National Library of Medicine. http://toxnet.nlm.nih.gov/cgibin/sis/search. Last accessed: 5/2013.

[2] P-P. Cui, L-F. Cui, L-L. Zhang, and D-F. Sun, Zeitschrift fur anorgaische und allgemeieneChemie, 2013 (in press DOI: 101002/zaac.201300141).

[3] R.C Nametz, Ind. Eng. Chem, 1967, 59, 99.

[4] T. Rajkumar, P. Sivasamy, B. Sreedhar, and C.T. Vijayakumar, Polymer Advanced Technologies, 2012, 23, 829

[5] W.C. Ying, R.R. Bonk , and S.A. Sojka, Envir. Prog, 1987, 6,4 .

[6] A.G. Thomas, and K.L. Syres, Chem. Soc. Rev, 2010, 41, 4207.

[7] K. Honda, J. Photochem Photobiol A- Chem, 2004, 116, 63

[8] A.J. Bard, J. Photochem Photobiol A- Chem, 1979, 10, 59

[9] T.N. Fujshima, D.A. Rao, and J. Tryk, J. Photochem Photobiol. C-Photochem Rev, 2000, 1, 1.

[10] M.R. Hoffmann, S. Martin, T. Cho, W.D.W. Behnemann, Chem. Rev, 1995, 95, 69

[11] S. Vijaikumar, N. Somassundaram, C. Srinivasan, Appl Catal A-Gen, 2002, 223, 129.

[12] J-M. Hermann, Catal Today, 1999, 53, 115.

[13] J.M. Pettibone, D.M. Cwertny, M. Scherer, and V.H. Grassian, Langmuir, 2008, 24, 6659.

[14] J. Tao, T. Luttrell, J. Bysma, and M. Batzill, 2011, J. Phys Chem, 2011, 21, 2407.

[15] W. Plazinski, W. Rudzinski, W, and Plazinska, A, Adv Colloid Interfac Sci, 2009, 152, 2.

[16] L.M. Sanctuary,'Physical chemistry' $4^{\text {th }}$ ed., Houghton Mifflin company Publishers; 2002, p 931.

[17] E.A. Dietz, N.J. Corteucci, and K.F. Singley, J. Liq Chromatogr, 1993, 16, 3331.

[18] C.H. Giles, D. Smith, and A. Huitson, J Colloid and Interface Sciences, 1974, 47, 755. 
[19] C. Moreno-Castilla, Carbon, 2004, 42, 83.

[20] A.S. Al-Degs, M.I. El-Barghouthi, A.H. El-Sheikh, and G.M. Walker, Dyes and Pigments, 2008, 77, 16.

[21] S. Andinis, R. Cioffi, F. Montagnaro, F. Pisciotta, and L. Santoro, Appl Clay Sci, 2006, 31, 126.

[22] N. Boujelben, and J.B.Z. Elouear, J Hazard Mater, 2009 163, 376.

[23] M.D.C. Zenteno, R.C.A. de Freitas, R.B.A. Fernandes, M.P.F. Fontes, and C.P. Jordao, Water Air Soil Poll, 2013, 224, 1418.

[24] P.Z. Araujo, P.J. Morando, and M.A. Blesa, Langmuir, 2005, 21,3470 .
[25] D. Robert, S. Parra, C. Pulgarin, A. Krzton, and J.V. Weber, Appl surf Sci, 2000, 167, 51.

[26] Y.C. Wong, Y.S. Szelo, W.H. Cheung, G. Mckay, 2003, Langmuir 19, 7888.

[27] V.K. Gupta, B. Gupta, A. Rostogi, and S. Agarwai, J Hazard Mater, 2011, 186, 891.

[28] T.S. Anirudhan, L. Divya, J. Parvathy, Journal of Chemical Technology and Biotechnology, 2012, 88, 878-886.

[29] M. Alkan, M. Karadas, M. Dogan, O. Demirbas, Journal of Colloid and Interface Science, 2005, 291, 309-318. 